ORIGINAL ARTICLE

\title{
Sudden infant death syndrome in child care settings in the Netherlands
}

\author{
G A de Jonge, C I Lanting, R Brand, J H Ruys, B A Semmekrot, J P van Wouwe
}

Arch Dis Child 2004;89:427-430. doi: 10.1136/adc.2003.029884

See end of article for authors' affiliations .....................

Correspondence to: Prof. G A de Jonge, Em. Professor of Paediatrics, Free University,

Amsterdam, Prins

Bernhardlaan 50, $2341 \mathrm{KL}$ Oegstgeest, Netherlands; ¡h@janruys.demon.nl

Accepted 12 August 2003
Background: In the Netherlands, there is a very low incidence of sudden infant death syndrome (SIDS) due to effective preventive campaigns.

Methods: During the period September 1996 to August 2002, nationwide 161 deaths from SIDS (about $85 \%$ of all cases of SIDS during that time) were investigated by the Cot Death Committee of the Dutch Paediatric Association.

Results and Discussion: Over 10\% of cases of SIDS took place during some type of child care. From a national survey carried out in 2000/01 information was available on the child care attendance of 2000 Dutch infants aged 3-6 months. Based on the hours usually spent in child care by these infants, the number of similarly aged infants that died from SIDS while attending child care was 4.2 times higher than expected. Remarkably, the prevalence of known risk factors for SIDS, such as sleeping position and parental smoking, was favourable in the SIDS cases in child care settings. The adherence of child care facilities to the safe sleeping recommendations is high in the Netherlands, and no explanation as to why child care settings may be associated with an increased risk of SIDS is apparent. The possibility of other explanations, such as stress and change in routine care, is hypothesised. n a retrospective study of 1916 SIDS cases from January 1995 to June 1997 in 11 states of the USA, it was stated by Moon et al that a large proportion (14.7\%) occurred in organised child care settings-that is, child care centres (CCC) or family (non-relatives) child care homes (CCH). Compared with SIDS in infants in the care of parents or guardian, these SIDS cases in child care settings were more likely to occur on weekdays between 800 am and 400 pm; infants were older, not black, more likely to be placed prone or found prone (the preferred sleep position being side or supine), and their mothers were more educated. ${ }^{1}$ Avoidance of prone infant sleeping, smoke exposure, soft bedding, and unsafe sleep environments is not universally practised in these settings. ${ }^{2}$ According to the US Census Bureau, in 1994, $17 \%$ of US infants $<1$ year of age were attending some type of organised child care. Moon et al estimated that infants in child care spent about $40 \%$ of the maximal time in that setting, and extrapolated that about $7 \%$ (17\% of infants $\times$ $40 \%$ of time) of deaths attributed to SIDS could be expected to occur in organised child care settings.

Since September 1996, sudden infant death syndrome (SIDS) in the Netherlands has been closely monitored by the Cot Death Committee (Landelijke Werkgroep Wiegendood, LWW) of the Dutch Paediatric Association (section Paediatric Intensive Care). In the present study we report on (1) the percentage of cases of SIDS occurring in child care settings, and (2) the pattern of risk factors for SIDS inside versus outside child care settings.

\section{METHODS}

From September 1996 to August 2002 the LWW evaluated 161 SIDS cases in the Netherlands (approximately 85\% of all cases). Within the first weeks or months after the infant's death a paediatrician (LWW member) conducted an extensive parent interview in the infant's home. In most cases of death occurring in child care, a second interview was conducted in the child care setting. The interviews were combined with an inspection of the death scene. After written consent of the parents, medical reports of the child were obtained. In some cases microscopic slides were reexamined by a paediatric pathologist (LWW member). Contrary to the usual definition, the LWW uses as the definition of SIDS the sudden, unexpected death of a child younger than 2 years old, which is not fully explained by the observed paediatric and pathological findings.

Child care setting was defined as a child care centre (CCC, "kinderdagverblijf") or a non-relatives family child care home (CCH, "gastouderadres"), both requiring payment, for young children (0-3 years old). Generally, in a CCC children are not allowed to attend when they are ill. For a $\mathrm{CCH}$ this is not always the case.

The comparison of the incidences of SIDS inside versus outside child care, is limited to infants older than $2 \frac{1}{2}$ months ( 10 weeks), the age at which in the Netherlands the legal maternity leave ends, and organised child care usually starts. In the six years of the study not a single case of SIDS under 12 weeks of age in a child care setting was reported. Moreover the comparison of these two incidences was limited to the five working days Monday to Friday, and the time during which in the Netherlands child care is available-that is, between $800 \mathrm{am}$ and $500 \mathrm{pm}$. The "probable hour of death" was arbitrarily calculated by estimating the time of death as halfway between the time the infant was last observed and the time it was found dead.

The time spent inside and outside child care in the general population was taken into account when comparing the incidence of SIDS inside and outside child care during the defined period-that is, on working days between $800 \mathrm{am}$ and $500 \mathrm{pm}$.

The control group consisted of 2000 infants aged 36 months in a representative national survey in 2000/01.

Abbreviations: $\mathrm{CCC}$, child care centre; $\mathrm{CCH}$, child care home; LWW, Landelijke Werkgroep Wiegendood; SIDS, sudden infant death syndrome 


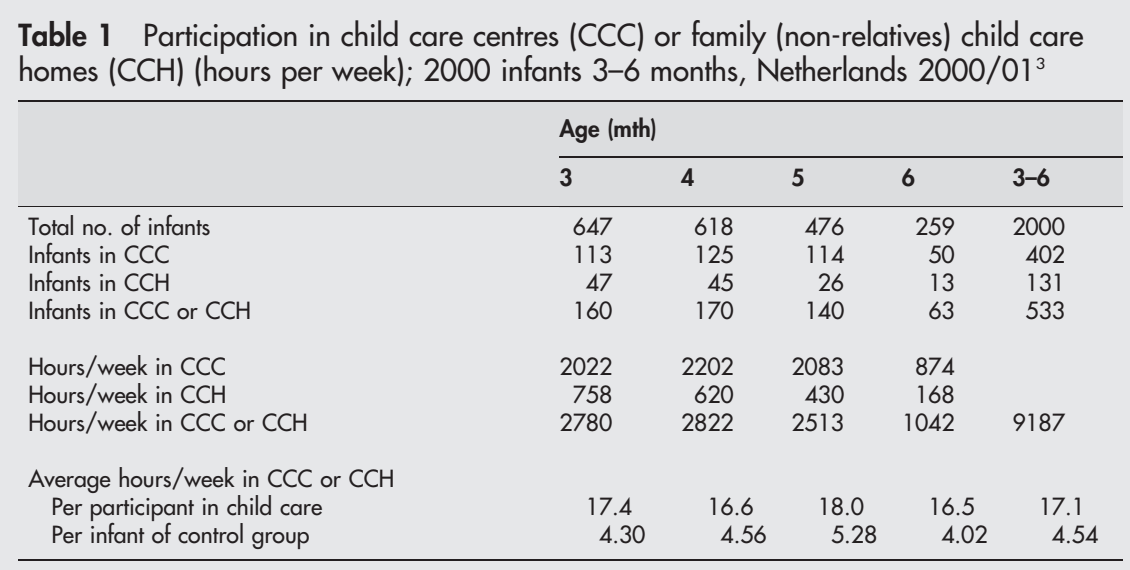

Infants of the control group, who participated in child care, stayed on average 17.1 hours per week in the CCC or CCH. However, $73 \%$ of these control infants did not attend any child care centre or home, so the average weekly stay in child care was only 4.5 hours for all control infants (table 1). ${ }^{3}$ Assuming some underestimation of the time spent in child care, we presume that on average six hours per week or 6 out of $45(5 \times 9)$ hours were spent in child care. This ratio $6: 45$ is used as an (externally defined) reference ratio to compare the observed and expected numbers of SIDS in and outside child care using a $\chi^{2}$ test. The accepted level of significance was $p<0.05$. Confidence intervals of the percentages of observed numbers of SIDS in child care settings were calculated.

For the sake of comparability the results of this study group are focused on SIDS cases of 3-6 months of age because the control group consisted of infants of the same age. However, older SIDS cases are shown as well in table 2.

Risk factors for SIDS were divided into three categories: non-preventable factors (sex, birth order, birth weight, low social level) and preventable factors (sleeping position, bed materials, parental smoking habits), as established in a series of Dutch research projects. ${ }^{4-7}$ Since 1987 the prevalence of these risk factors among infants in the general population has been established by representative national surveys in well-baby clinics every two years. ${ }^{8}$ Results of the survey of 1261 infants in 1999 which have been used in this study are presented in table 3.

\section{RESULTS}

\section{Incidence}

During the six years of study 17 SIDS cases (aged 310 months) of a total of 161 cases took place in a child care setting (nine cases in $\mathrm{CCC}$ and eight cases in $\mathrm{CCH}$ ) within the defined time period. A complete examination (both a paediatric examination and a postmortem examination) was performed in 12 cases, an incomplete examination in five cases. In all cases the standardised interviews were completed (table 2). In the same period, 19 cases of SIDS (16 cases 2-9 months of age and three cases 16-22 months old) occurred on a working day, as calculated between $800 \mathrm{am}$ and $5 ? 00 \mathrm{pm}$ outside child care settings (table 2).

Of the total of 36 SIDS cases, 25 were in the same age group as the control group of 3-6 months. Of these 25 cases, 14 died in child care. Based on the reference ratio of hours spent in child care of 6:45, the observed number of 14 cases was 4.2 times higher than the expected number of 3.3 cases

Table 2 Observed and expected number of SIDS cases in infants aged 21/2-23 months on Monday-Friday between 800 am and 500 pm outside child care settings (at home) and inside child care settings, if children in that age spend weekly 6 out of 45 hours in child care centres or family (non-relatives) child care homes (Netherlands, September 1996-August 2002)

\begin{tabular}{|c|c|c|c|c|c|c|c|}
\hline \multirow[b]{2}{*}{ Age (mth) } & \multicolumn{3}{|c|}{ Cases of SIDS } & \multicolumn{4}{|c|}{ In child care setting } \\
\hline & Total & At home & Child care & Observed (\%) & Expected (\%) & p value* & $\mathrm{Cl} \dagger$ \\
\hline $2 \frac{1}{2}$ & 2 & 2 & 0 & & & & \\
\hline 3 & 4 & 3 & 1 & & & & \\
\hline 4 & 7 & 1 & 6 & $14(56)$ & $3.3(13)$ & $<0.001$ & 35 to 76 \\
\hline 5 & 7 & 4 & 3 & & & & \\
\hline 6 & 7 & 3 & 4 & & & & \\
\hline 7 & 1 & 0 & 1 & & & & \\
\hline 8 & 2 & 2 & 0 & & & & \\
\hline 9 & 2 & 1 & 1 & $3(33)$ & $1.2(13) \ddagger$ & 0.10 & 7 to 70 \\
\hline 10 & 1 & 0 & 1 & & & & \\
\hline 16 & 2 & 2 & 0 & & & & \\
\hline 22 & 1 & 1 & 0 & & & & \\
\hline $2 \frac{1}{2}-22$ & 36 & 19 & 17 & $17(47)$ & $4.8(13) \ddagger$ & $<0.001$ & 32 to 64 \\
\hline \multicolumn{8}{|c|}{$\begin{array}{l}\text { * } \chi^{2} \text { test, Monte Carlo. } \\
\text { †95\% confidence interval of the observed percentage. } \\
\text { tData mentioned for completeness, based on the assumption that the ratio of } 6: 45 \text { also holds for the group aged } \\
7 \text { months and older. }\end{array}$} \\
\hline
\end{tabular}


Table 3 Characteristics of SIDS inside and outside child care settings at the age of 36 months, Monday-Friday 800 am-5 00 pm (Netherlands, 1.9.1996-31.8.2002), and the prevalence of risk factors for SIDS in the general population $(n=1261)$ at the age of $3-$ 6 months in November/December $1999^{\circ} 9$

\begin{tabular}{|c|c|c|c|c|c|c|}
\hline & \multicolumn{2}{|c|}{ Child care 3-6 mth } & \multirow{2}{*}{$\begin{array}{l}\text { Risk factor } \\
\text { difference: child } \\
\text { care versus at home }\end{array}$} & \multicolumn{2}{|c|}{ At home $3-6 \mathrm{mth}$} & \multirow{2}{*}{$\begin{array}{l}\text { National survey } \\
3-6 \text { mth } \\
\%\end{array}$} \\
\hline & $n=14$ & $\%$ & & $n=11$ & $\%$ & \\
\hline \multicolumn{7}{|c|}{ Non-preventable risk factors } \\
\hline Male sex & 7 & 50 & + & 4 & 36 & 51 \\
\hline Birth order $>1$ & 6 & 43 & - & 7 & 64 & 53 \\
\hline Birth weight $<2500 \mathrm{~g}$ & 2 & 14 & - & 2 & 18 & 7 \\
\hline Low social level & 0 & 0 & - & 4 & 36 & 5 \\
\hline \multicolumn{7}{|l|}{ Preventable risk factors } \\
\hline Put prone to sleep & 2 & 14 & - & 3 & 27 & 8 \\
\hline Put on a side to sleep & 1 & 7 & - & 1 & 9 & 5 \\
\hline Use of a quilt & 0 & 0 & - & 3 & 27 & 18 \\
\hline Use of a pillow & 0 & 0 & - & 1 & 9 & 2 \\
\hline Bed sharing & 0 & 0 & - & 1 & 9 & 7 \\
\hline Maternal smoking & 0 & 0 & - & 4 & 36 & 21 \\
\hline Paternal smoking & 2 & 14 & - & 6 & 55 & 32 \\
\hline
\end{tabular}

$(6 / 45 \times 25)(p<0.001)$. In this age group the percentage of the expected number of cases of SIDS in child care is clearly outside the confidence interval of the percentage of the observed number of cases of SIDS.

\section{Risk factors}

Table 3 shows the characteristics of SIDS in the groups aged 3-6 months inside and outside child care. To facilitate comparison the relevant prevalences of risk factors for SIDS in the general population aged 3-6 months are also noted.

Although the groups are too small to reach definite conclusions, the number of unfavourable risk factors in 14 infants with SIDS in child care was much lower than in 11 infants with SIDS at home.

\section{DISCUSSION}

After the national campaign "Back to Sleep" which started in October 1987 in the Netherlands, the registered incidence of SIDS ( 0 to $<1$ year) decreased from 104 per 100000 live births in 1986 to 12 per 100000 in $2000 .{ }^{9}{ }^{10}$ As a consequence of this steep decrease, the number of patients in this study is rather small.

SIDS during office hours is not a rare phenomenon in the Netherlands: in six years (September 1996 to August 2002), 36 cases occurring on working days between 800 am and $500 \mathrm{pm}$ comprised $22 \%$ of a total of 161 SIDS cases.

The incidence of SIDS in child care settings on working days between 800 am and 500 pm was significantly higher than at home, especially in the age group 3-6 months. It is improbable that this finding is caused by underestimating the participation in child care based on a national surveillance in 2000/01, since child care participation has steadily increased from 1996 until recently. Thus the average participation over the entire period (September 1996 to August 2002) was certainly not higher than established in 2000/01 (table 1).

SIDS in child care now amounts to over $10 \%$ of the total incidence of SIDS (17/161) and is about four times higher than expected for infants of 3-6 months of age (table 2).

There is no evidence for the hypothesis that daytime SIDS is a separate entity and occurs in a different subpopulation of SIDS. Age distribution, gender, and birth order of daytime SIDS were not clearly different from the distribution in the general population.
Generally the child care centres and homes in the Netherlands now keep very strictly to the advice of the Dutch national consensus "Prevention of cot death". ${ }^{11}$ Against this advice two infants were put down to sleep in a prone position (one in a CCC, one in a CCH). In both cases this occurred after the explicit request of the parents, who placed their infant prone at home as a remedy for excessive crying. Even if these two cases were allocated to the at home group our results do not change.

One infant was put down on its side, because the child care attending person felt this was better since it had a cold. The infant was found in a side position, nearly face down.

Non-smoking rules were fully respected in both CCC and $\mathrm{CCH}$.

Notwithstanding the exceptions mentioned, since 10 out of 11 risk factors actually favour the children in child care centres, these factors cannot be an explanation for the increased risk of SIDS in the centres. This suggests that in the child care settings the level of safe sleep practices is rather high. This seems to be in contrast with the situation in the USA as described by Moon and colleagues. ${ }^{12}$ Furthermore, there was no indication for a low social level of the families struck by SIDS during child care.

This raises the question of another explanation for the relatively high incidence of SIDS in child care. Is it caused by the factor that is specific to all types of child care, namely being cared for outside the familiar, trustworthy home? What does it really mean for a young infant to be transported and handed over to one or more strange persons, to arrive in an often noisy and disordered situation? The surroundings are confusingly new-the dayroom, the bedroom, the sleeping accommodation, the various noises and unusual smells. All this will no doubt cause some stress in infants. ${ }^{12}$ Do we really know the possible repercussions for these unprepared and vulnerable beings, both awake and asleep? Is the relatively high incidence of SIDS in child care perhaps a further reason to prolong maternity leave after childbirth towards the age of 7 or 9 months in the Netherlands?

\section{ACKNOWLEDGEMENTS}

The LWW is financially supported by the Stichting Wiegedood, Noorden, Netherlands. 


\section{Authors' affiliations}

$\mathbf{G}$ A de Jonge, Em. Professor of Paediatrics, Free University, Amsterdam, Prins Bernhardlaan 50, 2341 KL Oegstgeest, Netherlands

R Brand, Dept of Medical Statistics, Leiden University Medical Center, Netherlands

C I Lanting, TNO-Prevention and Health, Postbox 2215, 2301 CE

Leiden, Netherlands

J H Ruys, Em. Professor of Neonatology, Leiden University Medical

Center, Reviuslaan 38, 2343 JR Oegstgeest, Netherlands

B A Semmekrot, Paediatrician-neonatologist, Dept of Paediatrics,

Canisius Wilhelmina Hospital, Postbox 9015, 6500 GS Nijmegen,

Netherlands

J P van Wouwe, Paediatrician, TNO-Prevention and Health, Postbox

2215, 2301 CE Leiden, Netherlands

From the Cot Death Committee (Landelijke Werkgroep Wiegendood) of the Dutch Paediatric Association

\section{REFERENCES}

1 Moon RY, Patel KM, McDermott Shaefer SJ. Sudden infant death syndrome in child care settings. Pediatrics 2000;106:285-300.

2 Moon RY, Biliter WM, Croskell SE. Examination of state regulations regarding infants and sleep in licensed child care centres and family child care settings. Pediatrics 2001;107:1029-36.
3 Lanting $\mathrm{Cl}$, Herschderfer K, Wouwe JP van, et al. Peiling melkvoeding van zuigelingen 2000/2001 en het effect van certificering op de borstvoedingsciifers. Rapport 2001.252 TNO Preventie en Gezondheid, Leiden, 2002.

4 Jonge GA de, Engelberts AC, Koomen-Liefting AJM, et al. Cot death and prone sleeping position in the Netherlands. BMJ 1989;298:722.

5 Engelberts AC, Jonge GA de. Choice of sleeping position for infants: possible association with cot death. Arch Dis Child 1990;65:462-7.

6 Engelberts AC. Cot death in the Netherlands. Amsterdam: VU University Press, 1991.

7 L'Hoir MP. Cot death; risk factors and prevention in the Netherlands in 19951996. Utrecht, 1998.

8 Jonge GA de, Hagen EEvan, Wouwe JPvan. Veilig slapen en wiegendood anno 1999. Tijdschr voor Jeugdgezondheidszorg 2000;32:112-15.

9 Jonge GA de, Burgmeijer RJF, Engelberts AC, et al. Sleeping positions for infants and cot death in the Netherlands 1985-91. Arch Dis Child 1993;69:660-3.

10 Netherlands Central Bureau of Statistics (CBS). Mortality by cause of death, by age and by sex (series A1). Yearly edition, up to 2000, edition 2002. Voorburg: CBS.

11 Velzen-Mol HWM, Burgmeijer RJF, Hofkamp M, et al. Consensus Preventie van wiegen-dood. Ned Tijdschr Geneeskd 1997;141:1779-83.

12 Simpson JM. Infant stress and sleep deprivation as an etiological basis for the sudden infant death syndrome. Early Hum Dev $2001 ; 61: 1-43$

\section{A carer's salute to dying children}

Children should be the inheritors of our future so adults rightly view their early death as tragedy. But dying may expose qualities including love and concern for others.

People may see their physical discomfort, but it often seems unencumbered by the adult dread of perpetual non-existence. As death approaches, most children face it frontally.

A patient, waiting without hope for operation and knowing his older brother died in the same situation of the same disease, still successfully started a business.

Another, warned against caring for children still opted for that and died early, graciously and rightly proud at death of the professional qualification she achieved.

Adults may have difficulty with their decisions but refusing treatment for apparently trivial reasons or the advanced giffing of coveted toys indicates personal and proper control.

Apt deaths in comfort and happy trust occur especially at home in the bosom of family. One, thus secured, died when brushing her hair some hours after playing scrabble with the boyfriend.

We are privileged to relate to them as unpretentiously they teach how to live death. All success is relative, rarely what could be wished so celebrate them, even dying, despite the anguish.

\section{F Carswell}

